\title{
Radial Keratotomy : Where did it go wrong?
}

\author{
S. P. B. PERCIVAL \\ Scarborough
}

\begin{abstract}
Summary
A prospective study was set up to determine the effectiveness, predictability, stability, safety and feasibility within the National Health Service of radial keratotomy. The methods adopted include a new simplified guide to surgery with a predicted accuracy in 84 of 100 operations. Ninety-six percent of eyes with myopia of $\mathbf{- 6 . 0 D}$ or less preoperatively were seeing $6 / 12$ or better six months after surgery. Refraction remained stable within a range $0.5 \mathrm{D}$ spherical equivalent between the first and sixth postoperative months in $96 \%$, between the first and twelfth postoperative months in $90 \%$ and between the first and second years in $100 \%$ of eyes examined. There were no cases of progressive hypermetropia. Sixty-four percent of the 61 patients admitted to postoperative symptoms. Three percent of eyes lost best corrected vision. The disappointments were few but were analysed in detail. The least reliable were found to be associated with the higher myopes requiring a $3.0 \mathrm{~mm}$ clear optical zone.
\end{abstract}

Despite a rapid expansion of the practice of radial keratotomy (RK) in Europe, it is estimated that less than $5 \%$ of ophthalmic surgeons in the United Kingdom practise the technique. Many are unwilling to adopt a new pattern of work into an already overloaded schedule and there is a need to assess the efficacy of this relatively new technique particularly in relation to the National Health Service (NHS).

In 1985 a prospective study was set up at Scarborough to answer three questions:

(1) Keeping techniques as simple as possible, is it safe and possible under the NHS?

(2) How accurate or predictable is it?

(3) What is the effect in the long term?

Material and Methods

One hundred consecutive eyes(Table I) from 61 patients underwent RK between November 1985 and November 1987. Thirtythree of the patients were males and 28 were females. The age range was 21 to 58 years. Criteria for entry into the study were myopia or myopic astigmatism with a spherical equivalent of between $-2.0 \mathrm{D}$ and $-10.0 \mathrm{D}$, correctable visual acuity (VA) to $6 / 12$ or better, a stable refraction over a three year period, no other ocular pathology, failure of contact lens wearing and informed consent.

Of the 100 eyes entered, all have been followed for a minimum of six months, 60 have been followed for one year and 20 have been followed for two years. The protocol adopted was as follows:

(1) Informed consent. Some $80 \%$ of persons making enquiries were eliminated before consultaion by the following procedure. First a letter was sent to the patient stating the necessary criteria for surgery, outlining the risks of surgery and asking for a doctor's referral letter. Specifically the letter stated that the operation worked by weakening the structure of healthy tissue, that there would be

Correspondence to: S P B Percival FRCS, Department of Ophthalmology, Scarborough Hospital, Scarborough, Yorkshire YO126QL.

Presented at the Annual Congress of the Ophthalmological Society of the United Kingdom, April 1988. 
increased vulnerability to blunt trauma, that complications such as infection could lead to a worsening of vision, that problems of glare and fluctuating vision after surgery were common, that irregular healing could lead to astigmatism and that there was no guarantee of success. On receipt of the referral letter an appointment was sent to the NHS clinic. On arrival the patient was shown a video for informed consent which detailed the possible problems that could be encountered after surgery and which included a question and answer sequence. A questionnaire was then provided to ensure that the patient had understood the video and this was then checked through by a nurse

(2) Preoperative consultation included assessment of motivation, refraction, an explanation of likely acuity from $70 \%$ correction, assessment of ocular dominance, keratometry, applanation tonometry and optical pachymetry using the Mishima-Hedbys centering device.

(3) The surgical plan was based on the Thornton $2 \%$ formula ${ }^{1}$ but grossly simplified. The basic myopia was calculated by refraction then modified: for

Table I Distribution of patients

\begin{tabular}{lrrrr}
\hline Myopia & $<-3.5 \mathrm{D}$ & $3.5-6.0 \mathrm{D}$ & $>-6.0 \mathrm{D}$ & Total \\
\hline N. of eyes & 45 & 35 & 20 & 100 \\
Patients*male & 16 & 7 & 10 & 33 \\
$\quad \quad \quad$ female & 10 & 13 & 5 & 28
\end{tabular}

*Where patients had two eyes falling into different groups, the patient was recorded with the eye of the more myopic group.

Table II Guide for correction of modified myopia

\begin{tabular}{lcc}
\hline $\begin{array}{l}\text { Modified } \\
\text { Myopia (D.) }\end{array}$ & $\begin{array}{c}\text { Optical } \\
\text { Zone }(\mathrm{mm})\end{array}$ & $\begin{array}{l}\text { Number } \\
\text { of cuts }\end{array}$ \\
\hline $1.0-2.1$ & 4.0 & 4 \\
$2.2-3.1$ & 4.0 & 8 \\
$3.2-4.1$ & 3.5 & 8 \\
$4.2-5.2$ & 3.0 & 8 \\
$5.3-7.0$ & 3.0 & 8 REDEEPEN \\
\hline
\end{tabular}

males $-0.2 \mathrm{D}$ was added for every three years of age under 30 years and subtracted for every three years over 30 years. For females $-0.2 \mathrm{D}$ was added for every three years under 34 years and subtracted for every three over 34 years up to the age of 42 years and thereafter a similar rule applied to that of men. $-0.1 \mathrm{D}$ was added for every $2 \mathrm{~mm} \mathrm{Hg}$. of intraocular pressure below $13 \mathrm{~mm} \mathrm{Hg}$. and subtracted for every $2 \mathrm{~mm} \mathrm{Hg}$. above $17 \mathrm{~mm} \mathrm{Hg}$. was added for each keratometry dioptre below 43.0D and subtracted for each full dioptre above 44.2D. - 0.1D was also added for each $0.02 \mathrm{~mm}$ of central corneal thickness above $0.53 \mathrm{~mm}$ and subtracted for each $0.02 \mathrm{~mm}$ below $0.50 \mathrm{~mm}$.

Surgery based on the modified myopia, was then carried out using the simple guide shown in Table II. In bilateral cases there was a general aim to undercorrect the nondominant eye by around $0.5 \mathrm{D}$ as the first procedure and for a time interval of at least two months before surgery to the second eye. Only three optical zone (OZ) markers were used. The incision depth using an adjustable diamond blade on a micrometer screw, was aimed at over $95 \%$ corneal thickness by adding to the central pachymetry reading $0.07 \mathrm{~mm}$ for a $3.00 \mathrm{~mm} \mathrm{OZ}, 0.08$ for a 3.5 $\mathrm{mm} \mathrm{OZ}$ and $0.09 \mathrm{~mm}$ for a $4.0 \mathrm{~mm} \mathrm{OZ}$. In 16 eyes an astigmatic element in excess of $-1.5 \mathrm{D}$ necessitated additional relaxing incisions : these were placed perpendicular to the steepest meridian between but not touching the radial incisions and tangential to a 6.0 $\mathrm{mm} \mathrm{OZ}$.

(4) Stages of surgery. The fixation axis was marked as recommended in the PERK study $^{2}, 2$ cc lignocaine was injected retrobulbarly, the $\mathrm{OZ}$ was marked, 4 or 8 radial cuts were made from the $\mathrm{OZ}$ towards the periphery stopping short of the limbus. For cases requiring 'redeepening' (Table II) a second pass was made outside the $6.0 \mathrm{~mm} \mathrm{OZ}$ together with central pricks at the $\mathrm{OZ}$ in order to maximise the depth of incision. Sixteen cuts were not practised as a primary procedure. Six eyes required an additional 4 or 8 cuts to improve unaided vision, how- 
ever the results from surgery in these eyes were recorded for purposes of the study before the additional cuts had been made.

(5) Postoperative care. The eye was padded for one night. The patient was discharged from hospital the following day using g.dexamethasone q.d.s. Patients returned for assessment of acuity, refraction and postoperative symptoms at one month, six months, one year and two years. Assessment of symptoms, whether these were disabling and possible disappointment with the result of surgery were made by an independent assessor using a written questionnaire.

\section{Results}

Six months after surgery 86 eyes were seeing $6 / 12$ unaided (Table III). $100 \%$ of eyes with preoperative myopia less than $-3.5 \mathrm{D}$ and $94 \%$ of eyes with preoperative myopia less than $-6.0 \mathrm{D}$ were seeing $6 / 12$ unaided. The 14 eyes unable to see $6 / 12$ unaided comprised:-

(a) intended undercorrection of one eye in four presbyopes $(6 / 18,6 / 18,6 / 36,6 / 24)$

(b) three eyes undercorrected where 4 additional cuts later brought the acuity to $6 / 9$ or better in two and to $6 / 18$ in the third $(6 / 18,6 / 18,6 / 36$ respectively)

(c) one high myope who later required an

Table III Postoperative unaided visual acuity at 6 months in 100 eyes.

\begin{tabular}{|c|c|c|c|c|}
\hline Myopia & $<-3.5 \mathrm{D}$ & $3.5-6.0 \mathrm{D}$ & $>-6.0 \mathrm{D}$ & Total \\
\hline $6 / 12$ or better & 45 & 30 & 11 & 86 \\
\hline $6 / 18-6 / 36$ & 0 & 4 & 4 & 8 \\
\hline $6 / 60-\mathrm{CF}$ & 0 & 1 & 5 & 6 \\
\hline
\end{tabular}

additional 8 cuts to achieve $6 / 9$ unaided $(6 / 60)$

(d) two eyes that remained undercorrected despite in one an additional 8 cuts $(6 / 60$, $6 / 60)$

(e) four eyes with myopia in excess of $-9.0 \mathrm{D}$ which were never expected to attain $6 / 12$ (6/24, CF, 6/60, 6/60)

At twelve months $84 \%$ of the 60 eyes examined were seeing $6 / 12$ or better.

Predictability (Table IV) was determined by analysing the number of results which fell within the range of planned treatment according to the guide shown in Table II. Refraction at six months showed that 16 eyes were outside the planned range : nine had been undercorrected (one by more than $1 \mathrm{D}$.) and seven had been overcorrected (two by more than 1D.) There was a spread of unpredictability among all degrees of myopia. In bilateral cases where the first eye gave an unpredicted result the parameters were altered for the second eye as it was found that the behaviour of the second eye would predictably follow that of the first eye.

Refraction remained relatively stable (Table V) and altered by less than 0.6D. between the first and sixth postoperative month in 96 eyes (mean change -0.1D). In 4 eyes there was a decay in effect by more than $-0.5 \mathrm{D}$. Between the first and twelfth postoperative months the refraction altered by less than $0.6 \mathrm{D}$ in $90 \%$ of the sixty eyes examined at one year and between the twelfth and twenty-fourth months in $100 \%$ of the 20 eyes examined at two years.

Symptoms of the 61 patients at six months are analysed in Table VI. In answer to the questionnaire, 39 patients admitted to symptoms although they were sometimes described as being present before surgery as well. Only two patients were disabled by

Table IV Predictability of results in 100 eyes according to correction of myopia as planned in Table II (numbers more than 1.0D outside planned range shown in parenthesis)

\begin{tabular}{lcccc}
\hline Myopia & $<-3.5 \mathrm{D}$ & $3.5-6.0 \mathrm{D}$ & $>-6.0 \mathrm{D}$ & Total \\
\hline N. predicted correctly & 40 & 28 & 16 & 84 \\
N. undercorrected & $1(0)$ & $6(1)$ & $2(0)$ & $9(1)$ \\
N. overcorrected & $4(0)$ & $1(1)$ & $2(1)$ & $7(2)$ \\
\hline
\end{tabular}


symptoms in that the starburst effect prevented them from driving at night. Six patients showed slight disappointment with the result of surgery and are examined in detail as they highlight well the problems that may confront the RK surgeon:

Case 1. Male aged 36: too long a transverse cut for astigmatism led to increased glare, loss of best corrected vision from $6 / 6$ to $6 / 9$ and still a need for distance glasses. In addition he now has hypermetropic astigmatism so cannot read with this eye and feels his binocularity has suffered. The error was surgical.

Case 2. Female aged 24: -6.5 D.was undercorrected with 8 cuts and an additional 8 cuts increased her glare, prevented her from driving at night, reduced her best corrected vision from $6 / 5$ to $6 / 6$ and she still required glasses for clear distance vision. Furthermore, the anisometropia resulted in headaches. She was left with the predicament of being unwilling to have surgery to the fellow eye which would relieve the headaches, because of possible increase in glare.

Case 3. Female aged 32: $-5.5 \mathrm{D}$. $-5.25 \mathrm{D}$. Bilateral undercorrection with further decay in effect over ensuing year. Left unaided vision improved from $6 / 36$ to $6 / 18$ with 4 additional cuts but associated with loss of best corrected vision from $6 / 5$ to $6 / 6$.

Case 4. Female aged 38: $-5.0 \mathrm{D}$. Postoperative vision $6 / 9$ unaided but continued decay in effect by
2.5D. over a two year period, the cause appeared to be insufficient depth to the incisions.

Case 5. Male aged 40: Obsessional neurosis undiagnosed before surgery, dissatisfied with an unaided vision of $6 / 6$ right, $6 / 9$ left.

Case 6. Female aged 25: $-4.5 \mathrm{D}$. corrected to $6 / 9$ unaided but complained of deterioration of vision towards the end of the day.

Complications are listed in Table VII and compared with the incidence described in the 411 eyes from the PERK study ${ }^{2}$ none were serious. An increase in astigmatism is a known association of $\mathrm{RK}^{2}$. The five cases suffering an increase of over $1.0 \mathrm{D}$. were highly myopic eyes requiring a $3.0 \mathrm{~mm} \mathrm{OZ}$. In no case did the induced astigmatism exceed 2.0D. and all patients were satisfied with the considerable improvement in unaided vision $(6 / 12,6 / 12,6 / 18,6 / 60,6 / 12$, respectively).

The highest myopes had the most to gain from surgery, but they also had the most to lose as is shown by Table VIII. Thirty three eyes required a $3.0 \mathrm{~mm} \mathrm{OZ}$ and compared to those requiring 4.0 or $3.5 \mathrm{~mm} \mathrm{OZ}$, they showed a significantly higher predisposition to unstable refraction, increasing astigmatism, postoperative symptoms and disappointment with the result achieved.

Table V Stability of refraction after surgery

\begin{tabular}{|c|c|c|c|c|c|c|}
\hline \multirow{2}{*}{$\begin{array}{l}\text { Dioptric change } \\
\text { (sper. equiv) }\end{array}$} & \multicolumn{3}{|c|}{ Between 1 month $\& 6$ months } & \multirow{2}{*}{$\begin{array}{c}\text { TOTALS } \\
100 \text { eyes }\end{array}$} & \multirow{2}{*}{$\begin{array}{l}\text { Between } \\
1 \text { mo \& } 1 \text { yr } \\
60 \text { eyes }\end{array}$} & \multirow{2}{*}{$\begin{array}{c}\text { Between } \\
1 \text { yr \& } 2 \text { yrs } \\
20 \text { eyes }\end{array}$} \\
\hline & $<-3.5 \mathrm{D}$ & $3.5-6.0 \mathrm{D}$ & $>-6.0 \mathrm{D}$ & & & \\
\hline 0 & 33 & 23 & 7 & 63 & 24 & 11 \\
\hline-0.1 to -0.5 & 9 & 6 & 9 & 24 & 20 & 6 \\
\hline$>-0.5$ & 0 & 2 & 2 & 4 & 6 & 0 \\
\hline+0.1 to +0.5 & 3 & 4 & 2 & 9 & 10 & 3 \\
\hline$>+0.5$ & 0 & 0 & 0 & 0 & 0 & 0 \\
\hline
\end{tabular}

Table VI Analysis of symptoms in 61 patients

\begin{tabular}{|c|c|c|c|c|c|c|c|}
\hline \multirow[t]{2}{*}{ Preoperative myopia } & \multicolumn{2}{|c|}{$<-3.5 \mathrm{D}$} & \multicolumn{2}{|c|}{$3.5-6.0 \mathrm{D}$} & \multicolumn{2}{|c|}{$>-6.0 \mathrm{D}$} & \multirow{2}{*}{$\begin{array}{c}\text { Total } \\
\%\end{array}$} \\
\hline & $\mathrm{n}$. & $\%$ & $\mathrm{n}$. & $\%$ & $\mathrm{n}$. & $\%$ & \\
\hline Glare or starburst & 10 & 38 & 10 & 43 & 12 & 80 & 52 \\
\hline Fluctuating vision & 6 & 23 & 12 & 39 & 8 & 53 & 43 \\
\hline Intermittent diplopia & 0 & & 1 & 2 & 5 & 33 & 10 \\
\hline No symptoms & 14 & 54 & 5 & 41 & 3 & 20 & 36 \\
\hline
\end{tabular}


Table VII Complications from 100 operations compared with incidence among 411 operations of the PERK study ${ }^{2}$

\begin{tabular}{lcc}
\hline & $\mathrm{n}$ & PERK \% \\
\hline Macroperforations & 0 & 2 \\
Epithelial erosions & 0 & 1 \\
$\uparrow$ Astigmatism $>1 \mathrm{D}$ & 5 & 10 \\
Corrected VA < Preop. & 3 & 13 \\
Disabling symptoms & 2 & 1 \\
\hline
\end{tabular}

Table VIII Incidence \% of hazards from using the $3.0 \mathrm{~mm}$ optical zone ( 33 eyes from 23 patients) compared with the 3.5 or $4.0 \mathrm{~mm} \mathrm{OZ} \mathrm{(67} \mathrm{eyes} \mathrm{from}$ 38 patients)

$3.0 \mathrm{~mm} \mathrm{OZ} 3.5$ or $4.0 \mathrm{~mm} \mathrm{OZ}$

(\%)

(\%)

\begin{tabular}{|c|c|c|}
\hline \\
\hline \multicolumn{2}{|l|}{$\begin{array}{l}\text { Refraction change } \\
>0.5 \mathrm{D} \text { between }\end{array}$} & 0 \\
\hline $\begin{array}{l}\text { Increased } \\
\quad \text { astigmatism }>1 D\end{array}$ & 15 & 0 \\
\hline $\begin{array}{l}\text { Postoperative } \\
\text { symptoms }\end{array}$ & 87 & 50 \\
\hline $\begin{array}{l}\text { Disappointment } \\
\text { with result }\end{array}$ & 9 & 1 \\
\hline
\end{tabular}

\section{Discussion}

In answer to the questions posed at the outset of this study, it is clear that RK is a safe procedure. There were no major complications (Table VII) and apart from decay in effect in 4 eyes, the resulting refraction was found to be stable after one month within a range of 0.5D. spherical equivalent. (Table V).

Despite the warnings by Deitz ${ }^{3}$ and others ${ }^{4.5}$, there have so far been no cases of progressive hypertropia beyond $+0.5 \mathrm{D}$. The effectiveness of RK is verified by 75 out of 80 eyes $(94 \%)$ with myopia of $-6.0 \mathrm{D}$. or less seeing 6/12 unaided postoperatively (Table III). The guide for surgery (Table II) is more simple than those previously described ${ }^{6}$ yet gave a predictable result in $84 \%$ of eyes (Table IV) an accuracy which compares well with other methods ${ }^{7,8,9}$ despite the use of preoperative optical rather interoperative ultrasonic pachymetry.
Although potentially time consuming, by using the methods described it was found that on average only 20 minutes of theatre time per week and three hours of outpatient time per month were required for the study of 100 operations over a two year period. The methods recommended are simple yet effective and feasible in the NHS setting.

So where did it go wrong? The answer to this may be analysed subjectively from the written questionnaire concerning symptoms and disappointment and objectively from the incidence of complications. Fifty five of the 61 patients were pleased with the result of surgery despite the admission of symptoms in $60 \%$. The symptoms (Table VI), were an anticipated part of the procedure, sometimes no worse than before surgery and provided informed consent is obtained should not be considered a reason for discarding the procedure. The aim to undercorrect the nondominant eye first tended to prevent disappointment and covered the eventuality of the unpredictable over-reaction to surgery in $7 \%$ (Table IV) and left the options if under-reaction $(9 \%)$ of either a further 4 or 8 cuts later or allowing residual myopia to offset future presbyopia. It also enabled an altering of parameters for greater accuracy in the second eye.

The six cases showing some disappointment include all three cases of loss of best corrected vision, the only serious complication encountered, and three of the four cases of decay in effect (the fourth was overcorrected at one month and did not stabilise until three months). The salutary lessons to be learnt from these cases are the importance of surgical accuracy (Cases 1 and 4), the importance of patient education as to possible undercorrection (Cases 2,3,4) and probable postoperative symptoms (Cases $1,2,3,4,6)$, and the importance of correct assessment of motivation (Case 5). Case 2 also reflects the problems of induced anisometropia in a patient unwilling to undergo surgery to the second eye.

Finally, it should be remembered that the higher myopes who have most to gain, also have the most to lose, as is demonstrated in Table VIII. 


\section{References}

${ }^{1}$ Thornton SP: Thornton Guide for Radial Keratotomy incisions and optical zone size. $J$ Refract Surg 1985, 1: 29-33.

2 Waring GO 111, Lynn MJ, Gelender $\mathrm{H}$ et al.: Results of the Prospective Evaluation of Radial Keratotomy (PERK) Study one year after surgery. Ophthalmology 1985, 92: 17798.

${ }^{3}$ Dietz MR, Sanders R: Progressive hyperopia in radial keratotomy. Ophthalmology 1986 93: 1284-8.

${ }^{4}$ Shivitz TA, Arrowsmith PN, Russell BM: Contact lenses in the treatment of patients with overcorrected radial keratotomy. Ophthalmology 1987, 94: 899-903.

${ }^{5}$ Waring GO 111, Lynn MJ, Culbertson W et al.:
Three year results of the PERK Study. Ophthalmology 1987, 94: 1339-54.

${ }^{6}$ Sanders DR and Deitz MR: Radial keratotomy predictability programs. In Sanders DR, Hofmann RF and Salz JJ: Eds refractive corneal surgery, Thorofare; Slack Inc. 1986, 81-107.

${ }^{7}$ Sanders DR, Deitz MR, Gallagher D: Factors affecting predictability of radial keratotomy. Ophthalmology 1985, 92: 1237-43.

${ }^{8}$ Lynn MJ, Waring GO 111, Sperduto RD: PERK Study Group. Factors affecting outcome and predictability of radial keratotomy. Arch Ophthalmol 1987, 105: 42-51.

${ }^{9}$ Shepard DD: Radial Keratotomy: analysis of efficacy and predictability in 1058 consecutive cases. Part 1: Efficacy. J Cataract Refract Surg 1986, 12: 632-43. 